\title{
Manajemen Produksi Terung (Solanum melongena L.) Hidroponik dalam GH dengan Aspek Khusus Pemupukan di Belanda
}

\section{Production Management of Hydroponic Eggplant (Solanum melongena L.) under Green House with Specific Aspect on Fertilization in The Netherlands}

\author{
Heru Setiawan, Ahmad Junaedi" dan M. Rahmad Suhartanto
}

Departemen Agronomi dan Hortikultura, Fakultas Pertanian, Institut Pertanian Bogor (Bogor Agricultural University), Jl. Meranti, Kampus IPB Darmaga, Bogor 16680, Indonesia

Telp.\& Faks.62-251-8629353 e-mail agrohort@apps.ipb.ac.id

*Penulis Korespondensi : junaedi_agr@yahoo.com

Disetujui : 25 Mei 2018 / Published Online 2 Januari 2019

\begin{abstract}
Eggplant (Solanum melongena L.) is one of tropical plants that cultivated using greenhouse in the Netherlands. This greenhouse can control environmental factors of plant such as temperature, humidity, light and $\mathrm{CO}_{2}$ levels. The objective of this research is to study fertilizer management process in the greenhouse. Fertilization management includes fertilizer demand planning, fertilizer organization, fertilizer application, and fertilizer monitoring. Eggplant cultivation in the greenhouse use soilless culture system that use rockwool as a medium for planting. Fertilization in the greenhouse use fertigation method. Fertigation is a fertilization method that is given simultaneously with irrigation. Irrigation systems in the greenhouse is drip irrigation. Drip irrigation allows the nutrient solution is given to the plant in small quantities and highly measureable through drip emitter. The use of fertigation systems combined with drip irrigation gives many benefits such as efficiency of water and fertilizer uses, labor saving, reducing environmental pollution and produce good quality product. The important factors that we need to consider when making nutrient solutions are $p H, E C$, and fertilizer compatibility. The $p H$ and EC values for eggplant nutrient solution were 5.2-5.5 and 1.6-3.0 mS cm respectively. Compatibility of fertilizer should be considered to prevent precipitation that can cause clogging in the drip irrigation system.
\end{abstract}

Keywords : drip irrigation, fertigation, green house

\section{ABSTRAK}

Terung (Solanum melongena L.) merupakan salah satu tanaman tropis yang dibudidayakan menggunakan rumah kaca di Belanda. Rumah kaca ini dapat mengatur faktor lingkungan tumbuh tanaman seperti suhu, kelembaban, cahaya dan kadar $\mathrm{CO}_{2}$. Tujuan penelitian ini yaitu untuk mempelajari proses manajemen pemupukan di rumah kaca. Manajemen pemupukan meliputi perencanaan kebutuhan pupuk, pengorganisasian pemupukan, pelaksanaan pemupukan, dan pengawasan pemupukan. Budidaya terung di rumah kaca menggunakan soilless culture system yang menggunakan rockwool sebagai media tanamnya. Pemupukan di dalam rumah kaca menggunakan metode fertigasi. Fertigasi adalah metode pemupukan yang dilakukan bersamaan dengan irigasi. Sistem irigasi di rumah kaca yaitu irigasi tetes. Irigasi tetes memungkinkan larutan hara diberikan kepada tanaman dalam jumlah yang kecil dan terukur jumlahnya melalui drip emitter. Metode fertigasi melalui sistem irigasi tetes memberikan banyak manfaat diantaranya efisiensi penggunaan air dan pupuk, hemat tenaga kerja, mengurangi terjadinya pencemaran lingkungan dan menghasilkan produksi yang berkualitas. Faktor penting dalam pembuatan larutan hara fertigasi yaitu $\mathrm{pH}$, EC, dan kompatibilitas pupuk. Nilai pH dan EC larutan hara untuk tanaman terung berturut-turut yaitu 5.25.5 dan 1.6-3.0 $\mathrm{mS} \mathrm{cm}^{-1}$. Kompatibilitas pupuk perlu diperhatikan untuk mencegah pengendapan yang dapat berakibat terjadinya penyumbatan pada sistem irigasi tetes.

Kata kunci: fertigasi, irigasi tetes, rumah kaca 


\section{PENDAHULUAN}

Terung (Solanum melongena L.) adalah salah satu jenis sayuran yang banyak disukai masyarakat Indonesia. Terung merupakan tanaman tropis (Firmanto, 2011). Terung memiliki potensi yang besar untuk dikembangkan karena kebutuhan pasar yang tinggi. Menurut Pusat Data dan Sistem Informasi Pertanian Kementerian Pertanian (2012), konsumsi terung pada tahun 2010 dan 2011 yaitu $2.5 \mathrm{~kg}$ per kapita per tahun. Produksi terung Indonesia dengan penanaman di lahan terbuka yaitu 545646 ton, sedangkan produktivitasnya sebesar 10.8 ton ha ${ }^{-1}$ (FAO, 2013). Produksi dan produktivitas terung di Belanda dengan penanaman di dalam rumah kaca secara berturut-turut yaitu 48000 ton dan 480 ton $\mathrm{ha}^{-1}$ (FAO, 2013). Perbedaan produksi dan produktivitas terung Indonesia dengan Belanda disebabkan oleh perbedaan varietas tanaman, teknik budidaya, dan iklim.

Teknik budidaya terung di Belanda menggunakan rumah kaca. Hal ini karena terung merupakan tanaman tropis, sedangkan Belanda memiliki iklim subtropis. Rumah kaca di Belanda memiliki teknologi yang maju sehingga mampu mengatur suhu, kelembaban, cahaya dan kadar $\mathrm{CO}_{2}$. Rumah kaca juga melindungi tanaman dari kondisi alam yang buruk seperti angin kencang dan hujan yang lebat. Produksi terung di dalam rumah kaca menghasilkan produktivitas yang tinggi dengan produk yang berkualitas, sehat, dan ramah lingkungan. Lingkungan yang ideal dan varietas yang unggul menyebabkan tanaman cepat berbuah. Keuntungan lainnya yaitu usia produktif tanaman yang panjang mencapai 10-11 bulan sejak ditanam. Aplikasi pestisida yang rendah dikarenakan bangunan rumah kaca melindungi tanaman dari serangan hama dan penyakit. Aplikasi pestisida yang rendah menyebabkan residu pestisida yang tertinggal pada buah menjadi rendah dan aman bagi konsumen. Manajemen pemupukan yang baik mencegah pencemaran air oleh pupuk yang dapat berakibat menurunnya kualitas air di lingkungan. Aplikasi pestisida yang rendah dan manajemen pemupukan yang baik telah berkontribusi dalam menjaga lingkungan dari pencemaran pestisida dan pupuk.

Salah satu faktor penting yang menunjang tingginya produktivitas terung di dalam rumah kaca yaitu pemupukan. Pupuk adalah bahan yang mengandung satu atau lebih unsur hara tanaman sedangkan pemupukan adalah kegiatan pemberian pupuk ke tanaman. Kegiatan pemupukan memiliki konsep 5 tepat, yaitu tepat jenis, tepat dosis, tepat waktu, tepat tempat, dan tepat cara. Pupuk dibagi menjadi pupuk makro dan mikro berdasarkan jumlah unsur esensial yang dibutuhkan tanaman. Metode pemupukan yang digunakan di dalam rumah kaca yaitu fertigasi melalui sistem irigasi tetes. Fertigasi merupakan pemberian pupuk ke tanaman melalui sistem irigasi sedangkan irigasi tetes adalah pemberian larutan hara atau air tetes demi tetes ke area perakaran tanaman dengan jumlah, durasi, dan waktu tertentu menggunakan drip emitter. Metode pemupukan ini disesuaikan dengan teknik budidaya tanaman yang menggunakan soilless culture system dengan media tanam rockwool.

Rumah kaca adalah solusi terbaik bagi negara subtropis seperti Belanda untuk dapat memproduksi terung. Kegiatan penelitian ini bertujuan untuk mempelajari proses manajemen pemupukan di rumah kaca.

\section{BAHAN DAN METODE}

Kegiatan penelitian dilaksanakan dari 5 April 2017 sampai 30 Juni 2017 di Provinsi Noord Brabant, Belanda. Pengumpulan data yang telah dilakukan meliputi pengambilan data primer dan data sekunder. Data primer merupakan informasi yang diperoleh secara langsung melalui pengamatan yang dilakukan di lapangan maupun diskusi langsung dengan karyawan dan manajer rumah kaca.

Data primer diperoleh dari aspek khusus pemupukan. Aspek khusus yang diamati terkait dengan pemupukan meliputi organisasi dan sistem pemupukan, ketepatan jenis pupuk yang digunakan, ketepatan dosis pupuk yang digunakan, ketepatan waktu pemupukan, ketepatan cara pemupukan, ketepatan tempat pemupukan, defisiensi unsur hara dan efisiensi tenaga kerja dan prestasi kerja yang dilakukan oleh pekerja. Data sekunder diperoleh dari studi pustaka dan mempelajari arsip yang tersedia, laporan bulanan, laporan tahunan, serta dari dokumentasi yang tersedia. Jenis data yang diperoleh adalah sejarah dan kondisi umum, kondisi iklim, kondisi tanaman, organisasi manajemen, data produksi, dan data realisasi pemupukan selama tahun 2016-2017.

Data primer dan sekunder yang dihasilkan dianalisis menggunakan metode kuantitatif dan kualitatif. Metode kuantitatif disajikan dengan nilai rata-rata dan presentase hasil pengamatan. Hasil olahan data tersebut disajikan dalam bentuk tabel atau grafik, kemudian dibahas secara deskriptif dengan membandingkan data terhadap standar yang ditetapkan oleh Gebroeders van Duijn BV dan pustaka. Metode kualitatif disajikan dengan mendeskripsikan data dan informasi yang diperoleh dari pemeliharaan hingga ke pascapanen. 


\section{HASIL DAN PEMBAHASAN}

\section{Keadaan Umum}

Belanda termasuk negara yang beriklim subtropis. Negara ini memiliki empat musim yaitu musim semi, musim panas, musim gugur, dan musim dingin. Suhu hariannya bervariasi dari $2^{\circ} \mathrm{C}$ sampai $6^{\circ} \mathrm{C}$ pada musim dingin dan $17^{\circ} \mathrm{C}$ sampai $20^{\circ} \mathrm{C}$ pada musim panas. Luas wilayah Belanda tidak terlalu besar sehingga tidak terdapat variasi suhu yang signifikan antara satu wilayah dengan wilayah lain di Belanda. Menurut klasifikasi Koeppen-Geiger, Belanda masuk kedalam kelompok iklim $\mathrm{Cfb}$ dimana memiliki iklim yang hangat dan lembab dengan rata-rata suhu pada bulan terpanas di bawah $22^{\circ} \mathrm{C}$ dan memiliki empat bulan atau lebih dengan suhu rata-rata di bawah $10^{\circ} \mathrm{C}$ (Weather Online, 2017).

Gebroeders Van Duijn BV telah berdiri sejak tahun 1962 di De Lier, Belanda yang bergerak pada usaha budidaya terung dan terletak di tiga lokasi berbeda di barat daya Belanda. Kantor pusat berada di Steenbergen, Belanda dengan rumah kaca seluas 8.5 ha. Lokasi kedua berada di Oosterland dengan luas rumah kaca 4 ha. Lokasi ketiga berada di Wesdorpe dan memiliki luas rumah kaca 10 ha. Total rumah kaca yang dimiliki adalah 22.5 ha.

Rata-rata produktivitas terung setiap tahun di lokasi Steenbergen mencapai 529.5 ton $\mathrm{ha}^{-1}$. Produksi ini diperoleh dari dua bangunan rumah kaca. Rumah kaca 1 memiliki luas 4 ha dan rumah kaca 2 memiliki luas 4.5 ha. Setiap rumah kaca dibagi menjadi 4 afdeling. Afdeling 1 sampai 4 berada di rumah kaca 1 sedangkan afdeling 5 sampai 8 berada di rumah kaca 2. Bangunan utama selain rumah kaca yaitu gedung sortasi dan grading, tempat penampungan air, dan parkiran serta rumah direktur Gebroeders van Duijn BV Steenbergen.

\section{Budidaya Terung di dalam Rumah Kaca}

Terung di Gebroeders van Duijn BV dibudidayakan di dalam rumah kaca yang sangat modern. Rumah kaca pada lokasi penelitian ini mampu mengatur faktor lingkungan tumbuh tanaman seperti suhu, cahaya, kelembaban udara, dan kadar $\mathrm{CO}_{2}$. Selain itu, dari segi kebutuhan hara tanaman, rumah kaca ini menggunakan sistem irigasi tetes yang dikombinasikan dengan fertigasi sehingga mampu memenuhi kebutuhan hara tanaman dengan efisien dan efektif. Perlengkapan lain yang mendukung dalam kegiatan budidaya yaitu penggunaan teknologi komputerisasi dalam pemeliharaan dan pemanenan. Setiap baris tanaman dilengkapi dengan chip yang menandai nomor baris. Alat khusus berupa scanner digunakan untuk memindai chip tersebut untuk menandai baris mana saja yang telah dipanen atau selesai dipelihara. Selanjutnya melalui scanner, data tersebut dikirim ke komputer server untuk dicatat.

Varietas terung yang digunakan Gebroeders van Duijn adalah Rosheen RZ dari Rijk Zwaan Company. Varietas ini memiliki bentuk oval dengan berat rata-rata berkisar antara 315-350 gram, berwarna ungu hingga kehitam-hitaman. Terung varietas ini mampu berbuah dengan cepat. Panen pertama dilakukan pada 35 HST (Hari Setelah Tanam). Panen dilakukan seminggu dua kali pada tanaman yang sama. Usia produktif tanaman mencapai 10-11 bulan dengan tinggi $4 \mathrm{~m}$ di akhir musim. Musim tanam dimulai pada 6 Desember 2016 (rumah kaca 1) dan 7 Desember 2016 (rumah kaca 2). Perusahaan tidak melakukan pembibitan sendiri. Bibit siap tanam dibeli dari perusahaan bibit. Bibit ini merupakan hasil grafting antara terung (batang atas) dan tomat (batang bawah). Bibit grafting ini memiliki keunggulan yaitu efisien dalam penyerapan air dan hara karena akar tomat lebih banyak dibanding akar terung. Akar tomat mampu tumbuh dengan baik di dalam media rockwool yang terbatas sedangkan terung (batang atas) mampu memaksimalkan potensi genetiknya dengan suplai hara dan air yang mendukung serta kondisi lingkungan yang terkontrol.

Rumah kaca dibersihkan terlebih dahulu sebelum penanaman, kemudian peralatan seperti rockwool slab, drip emitter, tali lanjaran, terpal penutup tanah, dan hanging gutter diganti. Rockwool slab baru diletakkan di atas hanging gutter dengan jarak antar rockwool slab $30 \mathrm{~cm}$. Rockwool slabs memiliki panjang $133 \mathrm{~cm}$, lebar $20 \mathrm{~cm}$, dan tinggi $7.5 \mathrm{~cm}$. Rumah Kaca 1 memiliki 320 baris sedangkan Rumah Kaca 2 memiliki 340 baris. Setiap baris pada Rumah Kaca 1 memiliki panjang 75 m, sedangkan Rumah Kaca 2 memiliki panjang $80 \mathrm{~m}$. Jumlah rockwool slabs pada setiap baris tanaman di Rumah Kaca 1 yaitu 46 rockwool slabs dan Rumah Kaca 2 memiliki 48 rockwool slabs. Setiap rockwool slabs ditanam 4 bibit terung. Total jumlah bibit yang dibutuhkan untuk dua rumah kaca yaitu 124160 bibit sehingga populasi tanaman per ha yaitu 14608 tanaman. Jarak tanam yang digunakan yaitu $1.6 \mathrm{~m}$ antar baris, $30 \mathrm{~cm}$ antar rockwool slabs di dalam baris dan $20 \mathrm{~cm}$ antar rockwool cube di dalam rockwool slabs. Bibit terung ini ditanam di rockwool cube yang memiliki panjang $7.5 \mathrm{~cm}$, lebar $7.5 \mathrm{~cm}$, dan tinggi $7.5 \mathrm{~cm}$. Bibit diletakkan di atas rockwool slabs yang telah dibuat lubang pada plastiknya. Bibit ditanam dengan pola zig-zag. Sebuah lidi ditancapkan dari rockwool cube hingga 
menembus ke rockwool slabs agar rockwool cube tidak bergeser. Fungsi lain batang lidi ini untuk menyangga bibit tanaman yang masih kecil. Drip emitter kemudian dipasang pada setiap rockwool cube. Jika setelah penanaman terdapat tanaman yang mati, maka tidak dilakukan penyulaman tanaman. Alasannya ruang kosong yang ada akibat tanaman yang mati dapat diisi kembali dengan cabang tanaman yang lain.

Kegiatan selanjutnya yaitu pemeliharaan. Pemeliharaan awal yaitu pembuangan tunas tomat di batang bawah bibit. Jika tidak dibuang, maka batang atas tidak akan tumbuh dengan maksimal. Berikutnya setiap tanaman terung dibuat dua cabang primer. Cabang primer dibuat pada $30 \mathrm{~cm}$ diatas pangkal batang. Kemudian pada salah satu cabang primer dibuat dua cabang sekunder. Cabang sekunder dibuat pada $20 \mathrm{~cm}$ diatas cabang primer sehingga terdapat satu cabang primer dan dua cabang sekunder yang dipelihara pada setiap tanaman. Setiap cabang tersebut ditali pada tali lanjaran agar dapat tumbuh tegak dan mampu menopang buah yang dihasilkannya. Agar tanaman bisa terus tumbuh ke atas, setiap seminggu sekali dilakukan pelanjaran. Hal ini dikarenakan pertumbuhan terung yang cepat dan aktif untuk tumbuh ke atas. Kegiatan pemeliharaan lainnya yaitu pengendalian hama dan penyakit. Hama dan penyakit masih menjadi masalah serius yang harus dikendalikan walaupun budidaya terung dilakukan di rumah kaca. Hama yang menyerang tanaman terung yaitu whitefly, thrips, spidermite, dan colorado beetle sedangkan penyakit yang menyerang yaitu crazy roots. Pengendalian secara biologis dan mekanis menjadi pilihan pertama yang dipilih sebelum kemudian dilakukan pengendalian kimiawi. Hal ini dilakukan karena regulasi yang sangat ketat mengenai penggunaan pestisida dalam produk pertanian oleh pemerintah dalam rangka melindungi konsumen.

\section{Pemanenan}

Panen adalah kegiatan yang dimulai dari pemotongan buah dari pohon hingga kemudian buah ditransportasikan ke bagian sortasi dan grading. Kegiatan panen dilakukan setiap hari sejak panen pertama pada 35 HST (Hari Setelah Tanam). Terdapat tiga blok pemanenan pada lokasi Steenbergen. Blok I adalah $70 \%$ dari total luas rumah kaca 1 sehingga jumlah baris yang dipanen yaitu 224 baris. Populasi tanaman yang dipanen kurang lebih 50176 tanaman. Blok I ini terdapat pada afdeling 1 dan 2 serta sebagian besar afdeling 3. Blok II adalah 30\% total luas rumah kaca 1 dan $40 \%$ total luas rumah kaca 2 sehingga terdapat 232 baris yang dipanen.
Populasi pada Blok II kuran lebih 54144 tanaman. Blok II berada pada sebagian kecil afdeling 3 kemudian afdeling 4, afdeling 5 dan sebagian besar afdeling 6 . Blok III adalah $60 \%$ dari luas total rumah kaca 2 dengan jumlah baris 204 baris. Populasi tanaman kurang lebih 48960 tanaman. Blok III berada pada sebagian kecil afdeling 6, afdeling 7 dan afdeling 8. Rotasi panen dilakukan setiap 3 hari sekali. Rotasi panen adalah interval yang dibutuhkan untuk kembali ke blok yang sudah dipanen. Blok I dipanen setiap hari Senin dan Kamis. Blok II dipanen setiap hari Selasa dan Jum'at. Blok III dipanen setiap hari Rabu dan Sabtu.

Kriteria buah yang siap dipanen yaitu buah yang memiliki berat minimal 250 gram. Selain itu, buah yang memiliki warna terlalu merah dan berbentuk abnormal harus dipanen. Panen dilakukan dengan cara memotong tangkai buah pada jarak 1-1.5 $\mathrm{cm}$ dari pangkal buah dengan gunting panen. Tangkai buah yang terpotong tidak boleh runcing karena akan merusak buah yang lain apabila dikemas. Selanjutnya terung disusun ke kotak panen dengan ukuran $60 \mathrm{~cm}$ x $40 \mathrm{~cm}$ x $40 \mathrm{~cm}$. Kotak panen ini dilengkapi dengan chip dan nomor. Buah terung disusun maksimal dua lapis di dalam kotak. Hal ini penting untuk memudahkan pekerja di bagian sortasi untuk memisahkan buah kelas 1 dan 2. Selanjutnya kotak berisi terung yang sudah tersusun rapi diletakkan digerbong pengangkut kotak panen. Jumlah maksimal kotak panen yang bisa dibawa oleh gerbong tersebut adalah 21 kotak. Buah terung yang dipanen dalam satu baris berkisar antara 15 sampai 20 kotak tergantung dengan produktivitas mingguannya. Setelah semua terung dalam baris dipanen, setiap kotak panen yang berisi buah terung di scan pada chip yang ada pada kotak menggunakan scanner yang dimiliki setiap pekerja untuk menandai kotak yang berisi terung. Gerbong yang penuh akan dibawa ke bagian sortasi dan grading. Sebelum proses sortasi dimulai, setiap kotak ditimbang dan datanya dikirim ke komputer server. Data tersebut kemudian diolah menjadi data produksi panen. Data produksi panen mingguan ditampilkan pada Gambar 1.

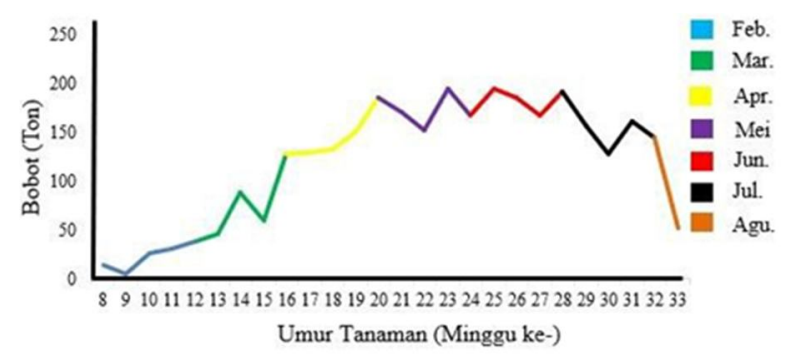

Gambar 1. Grafik produksi panen per minggu Gebroeders van Duijn B.V. pada tahun 2017 
Berdasarkan grafik yang ditampilkan pada Gambar 1 menunjukkan bahwa produksi mengalami fluktuasi namun cenderung meningkat mengikuti bertambahnya usia tanaman. Faktor musim berpengaruh sangat besar terhadap produksi yang dihasilkan. Musim dingin terjadi pada bulan Februari menyebabkan produksi tanaman rendah. Panjang hari yang pendek pada musim dingin menyebabkan tanaman tidak dapat berfotosintesis dengan maksimal. Produksi meningkat pesat pada musim semi yang terjadi pada bulan Maret hingga Mei. Panjang hari pada musim semi cukup lama sehingga produksi meningkat. Produksi cenderung menurun pada musim panas terjadi pada bulan Juni hingga Agustus. Produksi seharusnya semakin tinggi karena panjang hari yang diterima tanaman lebih panjang dibanding musim semi. Kendala utama pada musim panas yaitu serangan hama sangat tinggi sehingga terjadi penurunan produksi. Hama penting yang menyebabkan penurunan produksi yaitu Whitefly.

\section{Sortasi dan Grading}

Sortasi adalah kegiatan memisahkan atau memilah terung atas dasar perbedaan faktor mutu namun belum sampai ke tahap penggolongan tingkat mutunya. Jika kegiatan memisahkan atau memilah sampai ke tahap penggolongan tingkat mutu disebut grading. Kegiatan sortasi dan grading dilakukan secara bersamaan. Proses sortasi memisahkan buah dari kotoran seperti daun, ranting, dan buah yang tidak layak. Buah terung yang dianggap tidak layak adalah buah yang rusak, busuk, atau yang memiliki bentuk yang abnormal. Jika buah terung mengalami sedikit kerusakan, maka masih bisa diteruskan ke proses grading.

Proses grading dilakukan untuk mengelompokkan buah terung kedalam dua kelas produk, yaitu kelas 1 dan kelas 2. Perbedaan kelas ini ditentukan berdasarkan kriteria bentuk dan warna. Terung kelas 1 memiliki bentuk lonjong namun pada bagian ujung menggembung dan memiliki warna ungu atau ungu gelap, sedangkan terung yang memiliki bentuk abnormal, terdapat luka, dan berwarna merah masuk ke dalam kelas 2. Buah yang tidak masuk ke kelas 1 maupun kelas 2 akan dibuang. Semua buah terung yang diproses kedalam divisi sortasi dan grading tidak mengalami pencucian terlebih dahulu, artinya setelah dipanen, terung langsung dikemas. Hal ini dikarenakan terung dibudidayakan didalam rumah kaca dan minim penggunaan pestisida atau pun terdapat kotoran sehingga bisa langsung dikemas.

\section{Pemupukan}

Pemupukan bertujuan memberikan unsur-unsur hara yang dibutuhkan tanaman yaitu unsur makro dan mikro agar dapat tumbuh dan berproduksi maksimal. Manajemen pemupukan meliputi perencanaan kebutuhan pupuk, pengorganisasian pemupukan, pelaksanaan pemupukan, dan pengawasan pemupukan. Manajemen pemupukan yang baik sangat dibutuhkan agar tanaman dapat terus berproduksi dengan maksimal. Pemupukan diberikan ke tanaman bersamaan dengan irigasi atau biasa disebut fertigasi. Fertigasi dikombinasikan dengan sistem irigasi tetes untuk memberikan larutan hara ke tanaman. Melalui sistem ini, larutan hara diberikan ke setiap tanaman tetes demi tetes menggunakan drip emitter.

\section{Perencanaan Kebutuhan Pupuk}

Kebutuhan pupuk dihitung menggunakan software yang disebut Priva. Perhitungan ini diawali dengan penentuan konsentrasi larutan hara yang akan diberikan ke tanaman. Konsentrasi larutan hara ditunjukkan pada Tabel 1 dan Tabel 2. Setelah itu, konsentrasi larutan hara dikonversi oleh Priva menjadi resep pemupukan. Resep pemupukan menunjukkan jenis pupuk apa saja

Tabel 1. Konsentrasi larutan hara makro di Gebroeders van Duijn B.V. Steenbergen pada tanaman 1 BST sampai 5 BST tahun 2017

\begin{tabular}{lcccccccc}
\hline \multirow{2}{*}{ Umur Tanaman } & $\begin{array}{c}\text { Pengenceran } \\
\text { (kali) }\end{array}$ & $\mathrm{NH}_{4}^{+}$ & $\mathrm{NO}_{3}{ }^{-}$ & $\mathrm{H}_{2} \mathrm{PO}_{4}$ & $\mathrm{~K}^{+}$ & $\mathrm{Ca}^{2+}$ & $\mathrm{Mg}^{2+}$ & $\mathrm{SO}_{4}{ }^{2-}$ \\
\hline 1 BST* & 100 & 0.75 & 19.00 & 1.50 & 6.23 & 7.02 & 7.02 & 4.00 \\
5 BST** & 100 & 0.40 & 11.38 & 1.00 & 5.31 & 2.53 & 2.08 & 1.42 \\
5 BST** & 100 & 0.40 & 11.53 & 0.80 & 5.73 & 2.55 & 1.84 & 1.44 \\
5 BST** & 136 & 0.40 & 11.64 & 0.80 & 5.73 & 2.55 & 1.84 & 1.27 \\
\hline Standar 1 & 100 & 0.75 & 19.00 & 1.50 & 6.25 & 7.50 & 4.00 & 4.00 \\
\hline Standar 2 & 100 & 0.40 & 11.53 & 0.80 & 4.67 & 3.20 & 2.27 & 1.44 \\
\hline Rata-rata & 116 & 0.47 & 12.92 & 1.10 & 5.78 & 3.42 & 2.92 & 1.94 \\
\hline
\end{tabular}

Keterangan: BST: Bulan Setelah Tanam, Konsentrasi pemupukan tersebut digunakan sampai dikeluarkannya konsentrasi pemupukan yang baru, *Standar yang digunakan Standar 1 dengan nilai EC $3 \mathrm{mS} \mathrm{cm}-1$, **Standar yang digunakan Standar 2 dengan nilai EC $1,6 \mathrm{mS} \mathrm{cm}-1$ 
Tabel 2. Konsentrasi larutan hara mikro di Gebroeders van Duijn B.V. Steenbergen pada tanaman 1 BST sampai 5 BST tahun 2017

\begin{tabular}{|c|c|c|c|c|c|c|c|c|}
\hline \multirow{2}{*}{ Umur Tanaman } & \multirow{2}{*}{$\begin{array}{l}\text { Pengenceran } \\
\text { (kali) }\end{array}$} & \multirow{2}{*}{$\mathrm{EC}\left(\mathrm{mS} \mathrm{cm}^{-1}\right)$} & \multicolumn{6}{|c|}{ Hara Mikro $\left(\mathrm{mmol} \mathrm{L}^{-1}\right)$} \\
\hline & & & $\mathrm{Fe}^{3+}$ & $\mathrm{Mn}$ & $\mathrm{Zn}$ & $\mathrm{H}_{3} \mathrm{BO}_{3}$ & $\mathrm{Cu}^{+}$ & $\mathrm{MoO}_{4}{ }^{2-}$ \\
\hline $1 \mathrm{BST}^{*}$ & 100 & 3.0 & 45.0 & 10.0 & 10.0 & 45.0 & 2.0 & 1.0 \\
\hline $5 \mathrm{BST}^{* *}$ & 100 & 1.6 & 45.0 & 25.0 & 9.0 & 45.0 & 2.0 & 1.0 \\
\hline $5 \mathrm{BST}^{* *}$ & 100 & 1.6 & 52.0 & 22.0 & 8.0 & 45.0 & 2.0 & 1.0 \\
\hline $5 \mathrm{BST}^{* *}$ & 136 & 1.6 & 52.0 & 22.0 & 7.5 & 40.0 & 1.7 & 1.0 \\
\hline Standar 1 & 100 & 2.7 & 45.0 & 25.0 & 25.0 & 45.0 & 2.0 & 1.0 \\
\hline Standar 2 & 100 & 1.8 & 47.8 & 19.8 & 8.4 & 43.0 & 1.9 & 0.9 \\
\hline Rata-rata & 116 & 3.0 & 45.0 & 10.0 & 10.0 & 45.0 & 2.0 & 1.0 \\
\hline
\end{tabular}

Keterangan: BST: Bulan Setelah Tanam, Konsentrasi pemupukan tersebut digunakan sampai dikeluarkannya konsentrasi pemupukan yang baru

yang akan dilarutkan, berapa jumlahnya, dan pada bak mana pupuk tersebut dilarutkan.

Tabel 1 menunjukkan bahwa terdapat dua standar konsentrasi pemupukan yang digunakan. Perbedaan standar ini disesuaikan dengan fase pertumbuhan tanaman. Tanaman pada usia $1 \mathrm{BST}$ sampai 4 BST menggunakan standar 1 untuk konsentrasi pemupukan. Standar 1 memiliki nilai EC yang tinggi yaitu $3 \mathrm{mS} \mathrm{cm}-1$. Nilai EC yang tinggi menunjukkan jumlah unsur hara yang larut dalam larutan hara tinggi. Tanaman muda membutuhkan unsur hara dalam jumlah besar untuk mendukung pertumbuhan vegetatif dan generatif tanaman. Standar 2 digunakan pada 5 BST sampai 7 BST. Nilai EC pada standar 2 menurun menjadi $1,6 \mathrm{mS} \quad \mathrm{cm}-1$ untuk memperlampat pertumbuhan vegetatif tanaman sehingga tanaman tidak cepat tinggi. Tujuan lainnya yaitu untuk mencegah terjadinya akumulasi garam mineral pada media tanam.

Tabel 2 menunjukkan bahwa jumlah hara makro yang dibutuhkan sangat kecil dari pada unsur makro. Jumlah tersebut ditunjukkan dengan

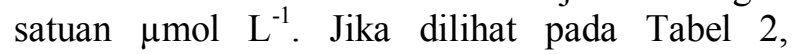
konsentrasi besi $(\mathrm{Fe})$ paling tinggi dibandingkan dengan konsentrasi larutan hara mikro lainnya. Konsentrasi paling rendah yaitu Molybdenum (Mo). Pengenceran dilakukan karena konsentrasi larutan hara pada bak pelarut masih tinggi. Nilai $\mathrm{pH}$ adalah nilai yang menyatakan derajat keasaman suatu larutan. Nilai EC digunakan sebagai indikator jumlah hara yang terlarut di dalam air. Nilai $\mathrm{pH}$ dalam larutan hara yaitu berkisar antara 5.2-5.5 sedangkan nilai EC larutan yaitu berkisar antara 1.6-3.0 $\mathrm{mS} \mathrm{cm}$.

Konsentrasi yang dibuat pada Tabel 1 dan Tabel 2 adalah konsentrasi pada larutan hara yang diberikan melalui drip emitter. Bak tersebut adalah Bak A dan Bak B. Setiap bak memiliki kapasitas maksimum $10000 \mathrm{~L}$ larutan hara. Konsentrasi larutan hara pada bak pelarut masih cukup tinggi sehingga dilakukan pengenceran.
Pengenceran dilakukan sebelum larutan hara dari Bak A dan Bak B disalurkan ke rumah kaca oleh Nutrient Dose and pH Control. Alat ini berfungsi untuk mengatur konsentrasi larutan hara, electrical conductivity dan $\mathrm{pH}$. Singh dan Bruce (2016) menyatakan bahwa Electrical conductivity atau disingkat $\mathrm{EC}$ adalah jumlah garam terlarut yang ada larutan hara. Pupuk yang dilarutkan pada umumnya berbentuk garam mineral yang apabila larut dalam air akan membentuk anion (ion bermuatan negatif) dan kation (ion bermuatan positif). Ion-ion ini menyebabkan konduktivitas (kemampuan larutan menghantarkan listrik) larutan hara meningkat. Oleh karena itu, EC digunakan sebagai indikator berapa banyak larutan hara yang terlarut didalam larutan hara. Sedangkan $\mathrm{pH}$ adalah memberikan informasi derajat keasaman (acidity) atau kebasaan (alkalinity) pada suatu larutan (Kaur dan Kumar, 2013). Kafkafi dan Tarchitzky (2011) menyatakan bahwa $\mathrm{pH}$ larutan hara mempengaruhi ketersediaan unsur hara bagi tanaman. Pada $\mathrm{pH}$ diatas 7.5-8.0, ketersediaan unsur $\mathrm{P}, \mathrm{Fe}, \mathrm{Mn}, \mathrm{B}$, $\mathrm{Zn}$, dan $\mathrm{Cu}$ bagi tanaman menurun. Sedangkan pada $\mathrm{pH}$ lebih rendah dari 5.0, unsur $\mathrm{N}, \mathrm{K}, \mathrm{Ca}$, dan $\mathrm{Mg}$ tidak tersedia bagi tanaman. EC dan $\mathrm{pH}$ larutan hara berturut-turut yaitu 1.8 sampai 3.0 dan 5.4 sampai 6). Hal ini sesuai dengan pernyataan Kafkafi dan Tarchitzky (2011) yang menyatakan bahwa derajat keasaman $(\mathrm{pH})$ yang sesuai untuk larutan hara bagi tanaman sayuran berkisar 5 5-6.8.

Jenis pupuk yang dilarutkan dan unsur hara yang dikandungnya dapat dilihat pada Tabel 3 sedangkan resep pemupukan dibagi untuk Bak A dan Bak B disajikan pada Tabel 4 dan Tabel 5. Pupuk dilarutkan pada bak yang terpisah karena beberapa unsur hara apabila dilarutkan dalam satu tempat yang sama dapat akan terbentuk endapan (precipitation). Magen (1996) menyatakan bahwa terbentuknya endapan akibat interaksi antar unsur hara juga menjadi masalah utama dalam fertigasi. 
Tabel 3. Jenis pupuk dan kandungan unsur hara yang dipakai di Gebroeders van Duijn B.V., Belanda tahun 2017

\begin{tabular}{lccc}
\hline Jenis Pupuk & Wujud & $\begin{array}{c}\text { Unsur } \\
\text { Hara }\end{array}$ & $\begin{array}{c}\text { Persentase } \\
\text { Unsur Hara (\%) }\end{array}$ \\
\hline Calsal & Cair & $\mathrm{Ca}$ & 17.5 \\
Magnitra & Cair & $\mathrm{Mg}$ & 10.0 \\
Amnitra & Cair & $\mathrm{N}$ & 18.0 \\
Fe-DTPA 6\% & Cair & $\mathrm{Fe}$ & 6.0 \\
Salpeterzuur 38\% & Cair & $\mathrm{N}$ & 8.5 \\
Kalisalpeter & Padat & $\mathrm{K}$ & 46.3 \\
Bitterzout & Padat & $\mathrm{S}$ & 32.0 \\
Monokaliumfosfaat & Padat & $\mathrm{P}$ & 52.0 \\
Calciumchloride & Padat & $\mathrm{Ca}$ & 99.0 \\
Multifeed B BigBag 1 & Padat & $\mathrm{S}$ & 18.2 \\
& & $\mathrm{P}$ & 3.2 \\
& & $\mathrm{~K}$ & 12.8 \\
Multifeed B BigBag 2 & Padat & $\mathrm{K}$ & 21.5 \\
& & $\mathrm{~S}$ & 11.4 \\
& & $\mathrm{P}$ & 4.9 \\
Mangaansulfaat 32.5\% & Padat & $\mathrm{Mn}$ & 32.5 \\
Zinksulfaat 24\% & Padat & $\mathrm{Zn}$ & 24.0 \\
Borax & Padat & $\mathrm{B}$ & 11.0 \\
Kopersulfaat 25\% & Padat & $\mathrm{Cu}$ & 25.0 \\
Natriummolybdaat 40\% & Padat & $\mathrm{Mo}$ & 40.0 \\
\hline
\end{tabular}

Pengendapan paling sering terjadi pada $\mathrm{Ca}$ dan $\mathrm{P}$ pada $\mathrm{pH}>$ 7.0. Pada kondisi ini, terbentuk endapan $\mathrm{K}_{2} \mathrm{SO}_{4}, \mathrm{CaSO}_{4}$ dan $\mathrm{NH}_{4} \mathrm{SO}_{4}$. Endapan ini akan menyebabkan penyumbatan (clogging) pada pipa atau drip emitter. Penyumbatan ini menyebabkan menurunnya efektivitas sistem drip irrigation sehingga berakibat penurunan hasil. Usaha untuk mencegah clogging yaitu dengan menyaring larutan hara, memastikan kompatibilitas hara yang dilarutkan dan menjaga $\mathrm{pH}$ larutan hara tetap asam (Liu dan McAvoy, 2012).

\section{Pembuatan dan Pemberian Larutan Hara}

Pembuatan larutan hara dimulai dari Bak A. Pada Bak A, kebanyakan pupuk yang digunakan adalah pupuk cair. Pupuk cair ini sebagian besar dimasukkan ke Bak A melalui pipa khusus yang menyalurkan pupuk dari tandon penyimpanan ke Bak A. Sebelum pupuk cair masuk ke Bak A, pupuk dihitung jumlahnya menggunakan alat khusus. Alat khusus ini akan menghitung jumlah pupuk yang lewat dari pipa ke Bak A dengan menghitung debit pupuk yang keluar dan berapa lama keran buka. Terdapat beberapa pipa yang menghubungkan tandon penyimpanan pupuk cair dengan alat ini, namun hanya ada satu pipa yang digunakan untuk menyalurkan pupuk cair dari alat tersebut ke Bak A. Oleh karena itu, sebelum dan setelah pupuk cair disalurkan ke Bak A, pipa tersebut dibersihkan dengan melewatkan air bersih selama beberapa saat hingga pipa bersih dari sisa pupuk cair. Hal ini dilakukan agar tidak terjadi reaksi kimia antar pupuk cair didalam pipa yang berakibat terbentuknya endapan. Pupuk cair yang dihitung dengan alat ini yaitu Amnitra, Magnitra, Calsal, Salpeterzuur, dan Fe-DTPA $6 \%$. Air dimasukkan kedalam Bak A dari pipa yang berbeda bersamaan dengan masukknya pupuk cair. Didalam Bak A, terdapat alat pengaduk yang secara konsisten mengaduk pupuk hingga menyatu dengan air. Pengaduk ini tidak pernah berhenti agar larutan hara tidak membentuk endapan.

Tabel 4. Resep pemupukan pada Bak A di Gebroeders van Duijn B.V., Belanda Tahun 2017

\begin{tabular}{lrrrrr}
\hline Jenis Pupuk & \multicolumn{4}{c}{ Tanggal } \\
\cline { 2 - 6 } & \multicolumn{1}{c}{$1-1-17$} & $3-5-17$ & $10-5-17$ & $18-5-17$ & $21-6-17$ \\
\hline Calciumchloride (kg) & 0 & 48.3 & 49.1 & 19.8 & 0 \\
Calsal (L) & 1492.6 & 467.3 & 471.6 & 709.4 & 767.7 \\
Magnitra (L) & 67.5 & 194.6 & 118.6 & 227.6 & 114.0 \\
Amnitra (L) & 27.5 & 50.2 & 50.2 & 34.0 & 39.3 \\
Kalisalpeter (kg) & 0 & 7.2 & 74.9 & 14.6 & 100.4 \\
Fe-DTPA 6\% (mL) & 31651.0 & 31807.0 & 36754.0 & 49817.0 & 46495.0 \\
\hline
\end{tabular}

Tabel 5. Resep pemupukan pada Bak B di Gebroeders van Duijn B.V., Belanda Tahun 2017

\begin{tabular}{|c|c|c|c|c|c|}
\hline \multirow{2}{*}{ Jenis Pupuk } & \multicolumn{5}{|c|}{ Tanggal } \\
\hline & $1-1-17$ & $3-5-17$ & $10-5-17$ & $18-5-17$ & $21-6-17$ \\
\hline Salpeterzuur 38\% (L) & 131.2 & 131.9 & 131.9 & 178.7 & 192.7 \\
\hline Kaliumchloride (kg) & 103.8 & 0 & 0 & 0 & 0 \\
\hline Kalisalpeter (kg) & 0 & 428.1 & 423.5 & 0 & 0 \\
\hline Bitterzout $(\mathrm{kg})$ & 229.0 & 350.9 & 355.6 & 34.3 & 143.1 \\
\hline Monokaliumfosfaat (kg) & 61.0 & 138.9 & 111.1 & 0 & 52.5 \\
\hline Multifeed BigBag 1 (kg) & 1200.0 & 0 & 0 & 0 & 0 \\
\hline Multifeed BigBag 2 (kg) & 0 & 0 & 0 & 1200.0 & 1200.0 \\
\hline Mangaansulfaat $32.5 \%(\mathrm{~g})$ & 4202.0 & 4223.0 & 3716.0 & 5037.0 & 4939.0 \\
\hline Zinksulfaat 24\% (g) & 2682.0 & 2426.0 & 2156.0 & 2740.0 & 2955.0 \\
\hline Borax $(g)$ & 4277.0 & 4298.0 & 3820.0 & 5178.0 & 5585.0 \\
\hline Kopersulfaat 25\% (g) & 496.0 & 499.0 & 436.0 & 592.0 & 638.0 \\
\hline Natriummolybdaat $40 \%(\mathrm{~g})$ & 242.0 & 243.0 & 243.0 & 329.0 & 319.0 \\
\hline
\end{tabular}


Setelah larutan hara untuk Bak A selesai, dilanjutkan ke pembuatan larutan hara pada Bak B. Pada Bak B, pupuk yang digunakan kebanyakan pupuk granular. Pupuk ini disimpan dalam wadah karung ata ember kecil (pupuk mikro). Pupuk-pupuk tersebut diangkut ke dekat Bak B untuk kemudian dilarutkan sesuai jumlah yang tertulis diresep. Timbangan diguanakan untuk menghitung jumlah pupuk yang akan diberikan. Pada pupuk yang berukuran besar seperti Multifeed BigBag, digunakan forklift untuk memasukkan pupuk kedalam Bak B. Setelah pupuk berada tepat diatas Bak B, dibuat lubang dibawahnya dan isi pupuk akan keluar. Sedangkan pupuk lain diangkut secara manual dan dimasukkan ke dalam Bak B. seperti Bak A, pada Bak $B$ juga terdapat alat pengaduk yang membantu melarutkan pupuk. Total larutan hara yang dibuat adalah 20000 L. Jumlah tersebut akan habis kurang lebih 5-7 hari pada cuaca yang baik. Pengarutan pemberian larutan hara dikontrol ditunjukkan pada Tabel 6 .

Tabel 6. Pengaturan pemberian larutan hara pada Tanggal 23 Juni 2017 di Gebroeders van Duijn B.V., Belanda Tahun 2017

\begin{tabular}{lccc}
\hline Periode & Fase 1 & Fase 2 & Fase 3 \\
\hline Waktu & $5: 28-$ & $7: 52-$ & $10: 18-$ \\
& $7: 52$ & $10: 18$ & $17: 37$ \\
Waktu tunggu minimal & $2: 00$ & $0: 15$ & $0: 08$ \\
Waktu tunggu maksimal & $24: 00$ & $0: 40$ & $0: 40$ \\
Radiasi matahari (J cm $\left.{ }^{-2}\right)$ & 409 & 436 & 364 \\
$\begin{array}{l}\text { Durasi (Menit) } \\
\text { Jumlah larutan per drip }\end{array}$ & 5 & 5 & 4 \\
emitter (mL) & 220 & 115 & 75 \\
$\begin{array}{l}\text { Rata-rata pemberian } \\
\text { larutan (L m }\end{array}$ & 0.327 & 0.171 & 0.112 \\
$\begin{array}{l}\text { Rata-rata jumlah larutan } \\
\text { yang diberikan (L) }\end{array}$ & 3184.5 & 1664.6 & 1085.6 \\
\hline
\end{tabular}

Terdapat tiga fase yang digunakan untuk mengatur pemberian larutan hara ke tanaman. Setiap fase memiliki rentang waktu yang berbeda beda. Pemicu sistem untuk aktif adalah jumlah radiasi matahari yang diterima oleh tanaman. Alat khusus yang disebut Climate Measurement Box ditempatkan pada setiap afdeling untuk menghitung jumlah radiasi matahari yang terima tanaman. Lamanya sistem aktif menentukan jumlah larutan hara yang keluar pada setiap drip emitter. Pengaturan pemberian larutan hara pada Tabel 6 dapat berubah seiring dengan perubahaan musim.

\section{Defisiensi Unsur Hara}

Defisiensi unsur hara adalah kondisi dimana tanaman kekurangan unsur tertentu sehingga pertumbuhan tanaman terganggu. Gejala yang timbul berbeda-beda tergantung unsur apa yang mengalami defisiensi. Defisiensi ini dapat disebabkan kekurangan unsur makro atau mikro. Pengamatan untuk melihat ada tidaknya defisiensi dilakukan dengan Leaf sampling Unit (LSU). Pada pengamatan ini diambil 10 tanaman contoh setiap rumah kaca. Setiap tanaman contoh diambil satu daun tua dan satu daun muda. Daun muda adalah daun ke-3 dari pucuk. Sedangkan daun tua adalah daun yang berada dibagian tengah tanaman. Setelah itu, daun tersebut akan dikirim ke laboratorium untuk dianalisis kandungan unsur kimia yang ada didalamnya. Hasil uji laboratorium menunjukkan unsur apa saja yang mengalami defisiensi. Hasil ini kemudian digunakan sebagai acuan untuk melakukan perubahan resep pemupukan.

\section{KESIMPULAN}

Kegiatan penelitian ini memberikan banyak pengalaman dan ilmu baru tentang budidaya tanaman terung di dalam rumah kaca khususnya pada aspek pemupukan. Manajemen pemupukan meliputi perencanaan kebutuhan pupuk, pengorganisasian pemupukan, pelaksanaan pemupukan, dan pengawasan pemupukan. Pemupukan di dalam rumah kaca menggunakan metode fertigasi. Fertigasi adalah metode pemupukan yang dilakukan bersamaan dengan irigasi. Sistem irigasi di rumah kaca yaitu irigasi tetes. Irigasi tetes memungkinkan larutan hara diberikan kepada tanaman dalam jumlah yang kecil dan sangat terukur jumlahnya melalui drip emitter. Metode fertigasi melalui sistem irigasi tetes memberikan banyak manfaat diantaranya efisiensi penggunaan air dan pupuk, hemat tenaga kerja, mengurangi terjadinya pencemaran lingkungan dan menghasilkan produksi yang berkualitas. Faktor penting dalam pembuatan larutan hara fertigasi yaitu $\mathrm{pH}, \mathrm{EC}$, dan kompatibilitas pupuk. Nilai $\mathrm{pH}$ dan EC larutan hara untuk tanaman terung berturut-turut yaitu 5.2-5.5 dan 1.6-3.0 mS cm$~^{-1}$. Kompatibilitas pupuk perlu diperhatikan untuk mencegah pengendapan yang dapat berakibat terjadinya penyumbatan pada sistem irigasi tetes.

Manajemen pemupukan yang baik menjadi salah satu faktor penting yang mempengaruhi produksi dan produktivitas tanaman. Faktor penting lain yang mempengaruhi produksi dan produktivitas tanaman yaitu serangan hama. Hama penting yang menyebabkan penurunan produksi pada tahun ini yaitu Whitefly (Bemicia tabaci). Pengendalian hama perlu dilakukan dengan hatihati agar kerugian dapat diminimalisir dan hama tidak resisten. 


\section{DAFTAR PUSTAKA}

[FAO] Food and Agriculture Organization. 2013. Eggplant production in Netherlands. http://www.fao.org/faostat/en/\#data/QC. [17 November 2017].

Firmanto, B. 2011. Sukses Budidaya Terung Secara Organik. Angkasa, Bandung.

Kafkafi, U., J. Tarchitzky. 2011. Fertigation a tool for efficient fertilizer and water management. International Potash Institute, Paris.

Kaur, B., D. Kumar. 2013. Development of automated nutrients composition control fertigation system. Journal of Computer Science, Engineering and Applications. 3(3): 67-78.

Liu, G., G. McAvoy. 2012. How to reduce clogging problems in fertigation. http://edis.ifas.ufl.edu/pdffiles/ HS/HS120 200.pdf. [22 September 2017].
Magen, H. 1996. Potassium chloride in fertigation. http://www.iclfertilizers.com/ Fertilizers/ Knowledge\% 20Center/KCl_in fertigation.pdf. [10 September 2017].

[Pusdatin] Pusat Data dan Sistem Informasi Pertanian. 2012. Statistik konsumsi pangan tahun 2012. http://pusdatin.setjen. pertanian.go.id/tinymcpuk/gambar/file/Stati stik Konsumsi_2012.pdf. [4 Februari 2017].

Singh, H., D. Bruce. 2016. Electrial conductivity and $\mathrm{pH}$ guide for hydroponics. http://pods.dasnr.okstate.edu/docushare/dsw eb/Get/Document-10397/HLA-6722web. pdf. [15 Agustus 2017].

Weather Online. 2017. The Netherlands. http://www.weatheronline.co.uk/reports/cli mate/The-Netherlands.htm. [4 September 2017]. 